\title{
The Efficacy of NIV in Pediatric Intensive Care Unit (PICU) with Respiratory Failure Admitted Patients
}

\author{
Anima Ferdous ${ }^{1 *}$, Manifa Afrin ${ }^{2}$, Mohammad Monir Hossain ${ }^{3}$ \\ ${ }^{I}$ Specialist,NICU \& PICU, MBBS, FCPS ( Pediatrics ), Universal Medical College Hospital, 74G/75,Peacock \\ Square, New Airport Road, Mohakhali, Dhaka 1215, Bangladesh \\ ${ }^{2}$ Associate professor(cc), Department of pediatrics, MBBS, DCH, MD (Pediatrics), Universal Medical \\ College,74G/75,Peacock Square, New Airport Road, Mohakhali, Dhaka 1215, Bangladesh \\ ${ }^{3}$ Professor, Department of Neonatal Medicine and NICU,MBBS, DCH, FCPS, MD. FRCP (Edin), FRCP \\ (Glasgow), FRCPCH (UK), PhD (DU), Bangladesh Institute of Child Health \& Dhaka Shishu (Children) \\ Hospital, Dhaka, Bangladesh, (Chief consultant, NICU \& PICU, Universal Medical College Hospital, \\ 74G/75,Peacock Square, New Airport Road, Mohakhali, Dhaka 1215, Bangladesh)
}

*Corresponding Author: Anima Ferdous, Specialist,NICU \& PICU, MBBS, FCPS ( Pediatrics ), Universal Medical College Hospital, 74G/75,Peacock Square, New Airport Road, Mohakhali, Dhaka 1215, Bangladesh, E-mail: anima.donna.af@gmail.com

\begin{abstract}
Background: Noninvasive ventilation (NIV) has now become an integral tool within the treatment of both acute and chronic respiratory failure, and at an equivalent time reducing the necessity for invasive ventilation.
\end{abstract}

Objective: To determinate the efficacy of NIV in pediatrics whom admitted to Pediatric intensive care unit (PICU) with respiratory failure.

Methods: This retrospective observational study allowed the accumulation of sufficient number of patients from reviewed electronic patients records (EPR) of the PICU at Universal Medical College Hospital, Dhaka, Bangladesh from January 2017 to December 2019 to select patient who required NIV, demographic and clinical data were collected before and after applying the NIV. The data included heart rate (HR), respiratory rate (RR), oxygen concentration (PO2) and CO2 concentration (PCO2).

Results: NIV was used for a total of 61 pediatric patients admitted to PICU during the period of the study. Pneumonia was the commonest indication for the NIV $(n=25,40.9 \%)$, and continuous positive airway pressure (CPAP) was used in 52(85.2\%) patients. The mean duration of NIV was $8 \pm 7.2$ days, there was a significant clinical improvement after one hour from application of NIV. The mean improvement in RR was from 48.4 \pm 2.2 to $35.0 \pm 1.5(P=0.000)$, SPO2 was improved from $88.1 \pm 1.8$ to $96.5 \pm 0.7(P=0.000)$, and the PCO2 was improved from $61.4 \pm 6.1$ to $48.7 \pm 3.7(P=0.002)$. Five patients were failing to respond to the NIV and shifted to mechanical ventilation.

Conclusion: The NIV is a useful tool for treatment of respiratory failure in pediatrics, especially under the age of one year. Pneumonia was the commonest indication for the use of the NIV. More investigation is needed to fully evaluate the ramifications of increased use of this technology in the PICU.

Keywords: Respiratory Failure; Noninvasive Ventilation; PICU; Pediatric Patients.

\section{INTRODUCTION}

The use of noninvasive ventilation (NIV) has become increasingly popular in the pediatric intensive care unit (PICU) over the last decade. This review intends to assess our current knowledge on the utilization of noninvasive support in children, especially focusing on its efficacy and safety profile.Breathing difficulties are common symptoms in pediatrics and one of the common reasons for visiting the emergency department, [1] invasive mechanical ventilation is still widely used in PICU for treatment of respiratory failure but with high risk sequel. The NIV has become a standard treatment of acute and chronic respiratory failure in children [2]. The advantages of NIV are widely reported in 
scientific literature. It is much safer than invasive mechanical ventilation. Compared to invasive ventilation, NIV lowers the risk of laryngeal swelling, post extubation vocal cord dysfunction, barotrauma/volutrauma, ventilatorassociated pneumonia. One can communicate with the patient and does not require deep sedation [3-6].The frequency of acute respiratory failure is higher in pediatric than adults and often precedes cardiopulmonary arrest. However, in adults primary cardiac disease is often responsible. Recent studies endorse the use of this therapy in the pediatric intensive care setting. NIV appears to be associated with a decrease in the intubation rate in children. Children who are responsive to NIV will usually show improvement in their physiologic parameters shortly after the initiation of this therapy and this improvement is often sustained. NIV is proving to be a welltolerated alternative to endotracheal intubation, in particular in those patients with primary respiratory failure, postsurgical patients or with post extubation respiratory distress. Most studies represent single-center experience and therefore caution must be exerted when attempting to generalize their results. Therefore, prompt recognition and treatment of pediatric patients with pending respiratory failure is lifesaving [7, 8].Respiratory failure is a syndrome in which the respiratory system fails in one or both of its gas exchange functions: oxygenation and carbon dioxide elimination. Patients with respiratory failure can be classified into two groups, depending on the component of the respiratory system that is involved: hypoxemic respiratory failure and hypercapnic respiratory failure [9-11].The aim of our study was to determinate the efficacy of NIV in pediatrics admitted to PICU with respiratory failure $\left(\mathrm{PCO}_{2}>50 \mathrm{mmHg}\right.$ or oxygen saturation $<90 \%$ ) over a 3 year period requiring respiratory support in form of NIV, and assess the possible correlative factors with response to NIV.

\section{MAterials AND MethodS}

This retrospective observational study allowed the accumulation of sufficient number of patients from reviewed electronic patients records (EPR) of the PICU at Universal Medical College Hospital, Dhaka, Bangladesh from January 2017 to December 2019 to select patient who required NIV. During their course of admission they assess initially and after one hour from initiation. In our PICU registry 416 patients were admitted from January 2017 and December 2019. Assisted ventilation was used for 177 (42.5\%) patients, among them 61 patients $(14.7 \%)$ required NIV for respiratory support.The extracted data included demographic characteristics of the patients, type of respiratory failure, clinical diagnosis and the indication of NIV.The decision of instituting the NIV was made by a PICU physician. NIV was considered as a treatment when the patient presented with acute hypercapnia $\left(\mathrm{PCO}_{2}>50\right.$ $\mathrm{mmHg}$ ) or hypoxemia (oxygen Saturation < $90 \%$ ) or both. The uses of CPAP versus BIPAP depend on age and weight. CPAP use for small patients less than $8 \mathrm{~kg}$ during the first year of life (mostly neonates).

Exclusion criteria were Glascow Coma Scale (GCS) of less than 8 or altered mental status in previously normal patients and cardio circulatory instability. Patients were divided in to 2 main groups according to primary diagnoses:

- Respiratory causes; included bronchialasthma, bacterial/viral pneumonia aspiration pneumonia, acute bronchiolitis and recurrent apneas.

- Non respiratory causes; included hematological/oncological (acute chest syndrome, and leukemia with septic shock), neurological (neuromuscular disease), postoperative extubation.

The collected data included a demographic variables like age and sex, primary and secondary clinical diagnoses. The type and duration of NIV required during that illness. The progress included need for intubation. Patient's clinical response was assessed by respiratory rate, oxygen saturation, heart rate and blood gas analysis $\left(\mathrm{PO}_{2} \& \mathrm{PCO}_{2}\right)$. We collected data from EPR before and after one hour from initiation of NIV (short-term effects). The criteria for failure of NIV were determined by persistence of severe respiratory distress without improvement in oxygenation $\left(\mathrm{O}_{2}\right.$ saturation $\left.<90 \%\right), \mathrm{pH}<7.2$, $\mathrm{PaCO}_{2}>50$ or continuum of apnoeic episodes after one hour of initiation of NIV.

\subsection{Statistical Analysis}

Statistical analysis was performed using the Statistical Package for Social Sciences (SPSS version 21.0), which was used for data entry and analysis. $\mathrm{P}$ value was used to test the significance of the results at the 5\% level.

\section{ReSUlts}

A total of 61 patient were admitted to the PICU and ventilated using NIV between January 2017 to December 2019 with mean age of $46.6 \pm(27.6)$ 
months, males to female ratio 1:1.26. Median weight was $3 \mathrm{~kg}$.According to the types of NIV, 52 patients $(85.2 \%)$ were ventilated using CPAP and 9 patients $(14.7 \%)$ were ventilated using a biphasic positive airway pressure (BIPAP). More than two third of the cases $(n=42,68.9 \%)$ required NIV for 1-5 days. The mean duration of NIV for the 61 patients was $8 \pm 7.2$ days [see Table 1].The clinical diagnosis as in [Table 2] showed respiratory diseases were the most frequent indication for NIV $(n=44,72.13 \%)$. Among them pneumonia was the commonest indication for NIV $(n=25,40.9 \%)$.[Table 3] reveals the physiological parameters that were used as criteria to monitor response before and after one hour from the start of NIV. The majority of patients showed significant improvement after one hour from application of

Table1: Demographic and clinical characteristics of pediatrics whom required $N I V(N=61)$

\begin{tabular}{|l|l|l|l|}
\hline \multicolumn{2}{|c|}{ Characteristics } & \multicolumn{1}{c|}{ No (n=61) } & Percentage (100.0) \\
\hline Sex : & Male & 34 & 55.73 \\
\hline & Female & 27 & 44.26 \\
\hline Age : & 12 months & 32 & 52.5 \\
\hline & 12 months - <5 years & 20 & 32.8 \\
\hline \multicolumn{2}{|c|}{ years } & 09 & 14.7 \\
\hline Types of NIV: CPAP & 52 & 85.2 \\
\hline \multicolumn{2}{|c|}{ BIPAP } & 09 & 14.7 \\
\hline Duration of NIV: $<1$ day & 14 & 22.9 \\
\hline \multicolumn{2}{|c|}{ 1--5 days } & 42 & 68.9 \\
\hline Outcome : Successful wean NIV: & 05 & 08.2 \\
\hline \multicolumn{2}{|l|}{ Failed NIV * } & 56 & 91.8 \\
\hline *Failed NIV shifted to mechanical ventilation. Three were improved and successfully extubated, while two were \\
Expired.
\end{tabular}

Table2: The clinical diagnosis of pediatrics whom admitted to PICU and required NIV $(N=61)$

\begin{tabular}{|l|l|l|l|}
\hline \multicolumn{2}{|c|}{ Characteristics } & \multicolumn{1}{c|}{ No (n=61) } & Percentage (100.0) \\
\hline Respiratory diagnoses & & \\
\hline- & Pneumonia & 25 & 40.9 \\
\hline- & Bronchopneumonia & 6 & 9.8 \\
\hline- & Bronchiolitis & 6 & 9.8 \\
\hline- & Aspiration pneumonia & 4 & 6.5 \\
\hline- & Recurrent apnea & 2 & 3.2 \\
\hline- & Asthma & 1 & 1.6 \\
\hline Non respiratory diagnoses & & \\
\hline- & Hematology ${ }^{*}$ & 6 & 9.8 \\
\hline- & Immunology & 2 & 3.2 \\
\hline- & Neurology & 8 & 13.1 \\
\hline- & Postoperative & 1 & 1.6 \\
\hline & $*$ eg: SCD \& leukemia, ${ }^{* *}$ eg: myopathy \& GBS. & \\
\hline
\end{tabular}

Table3: The physiological parameters that were used as criteria to monitor response before and after one hour of start NIV $(N=61)$

\begin{tabular}{|l|l|l|l|l|}
\hline \multicolumn{1}{|c|}{ Characteristics } & \multicolumn{1}{|c|}{ Before NIV } & \multicolumn{1}{c|}{ After NIV } & \multicolumn{1}{c|}{ Percentage of difference } & P value \\
\hline & & & & \\
\hline Heart rate & $141.9 \pm 3.7$ & $132.6 \pm 3.4$ & $-9.2 \pm 2.9$ & 0.002 \\
\hline Respiratory rate & $48.4 \pm 2.2$ & $35.0 \pm 1.5$ & $-13.3 \pm 1.9$ & 0.000 \\
\hline $\mathrm{O}_{2}$ concentration & $88.1 \pm 1.8$ & $96.5 \pm 0.7$ & $8.3 \pm 1.7$ & 0.000 \\
\hline $\mathrm{CO}_{2}$ concentration & $61.4 \pm 6.1$ & $48.7 \pm 3.7$ & $-12.6 \pm 3.7$ & 0.002 \\
\hline
\end{tabular}

$48.4 \pm 2.2$ to $35.0 \pm 1.5 \quad(\mathrm{P}=0.000), \quad \mathrm{O} 2$ concentration improved from $88.1 \pm 1.8$ to $96.5 \pm 0.7(\mathrm{P}=0.000)$, and the $\mathrm{CO} 2$ concentration 0.002).Patients were monitored closely for signs patients were failed to respond to NIV after the initial one hour of monitoring, and were shifted mechanical venlation. Three had pneumonia successfully extubated, while two were expired, first one has prematurity and recurrent apnea primary disease and no delay concerning respiratory support. improved from $61.4 \pm 6.1$ to $48.7 \pm 3.7(\mathrm{P}=$ 


\section{DISCUSSION}

The current study showed our experience in NIV in Universal Medical College Hospital, Dhaka, Bangladesh over 3 years in PICU from January 2017 to December 2019 in Bangladesh. Acute respiratory insufficiency/ distress in pediatric patients admitted to PICU can improve with NIV. The clinical evidence of the response was determined by improvement in physiological parameters (RR and HR) as well as biochemical indices in the blood gases $\left(\mathrm{PO}_{2}\right.$ and $\mathrm{PCO}_{2}$ ).Pneumonia was the major cause for the NIV among the primary respiratory diseases $40.9 \%$, and bronchiolitis $9.8 \%$. Compared with non-respiratory diseases, our results were comparable to the percentages in the study which was done by Clara Abadesso et al. [12] in which Main diagnoses were bronchiolitis in 102 $(67.5 \%)$, and pneumonia in $44(29 \%)$ patients [13]. From the first hours of use of the NIV, the improvement was evident, and statistically significant, the mean difference in the respiratoryrate was $-13.3 \pm 1.9$ breaths per minute $(\mathrm{P}=0.000)$, in $\mathrm{PaO} 2$ was $8.3 \pm 1.7 \mathrm{mmHg}$ $(\mathrm{P}=0.000)$ and in $\mathrm{PaCO}_{2}$ was $12.6 \pm 3 \mathrm{mmHg}(\mathrm{P}$ $=0.002)$. This result was similar to the study done by Yañez LJ et al. [14] which found that heart rate and respiratory rate were significantly lower after 1 hour of treatment using NIV compared with admission $(\mathrm{p}=0.0009$ and $\mathrm{p}=0.004$, respectively) [15].Our study showed early improvements in the HR and PCO2 in comparison with a study done by Muñoz-Bonet JI et al. [15] in the Predictive factors for the outcome of NIV in pediatric acute respiratory [12]. In this study, independent risk factors for NIV failure were apnea, pneumonia and septic shock. These factors were also identified in previous studies done by Clara Abadesso et al. [12]. Essouri et al. [17] showed that NIV decreased inspiratory muscle effort in children with acute moderate hypercapnic insufficiency, measured by e sophageal and diaphragmatic pressure time product. Another study was done by Essouri $\mathrm{S}$ et al. [13] and concluded that NPPV was able to improve clinical outcome in young patients admitted to the PICU for acute moderate hypercapnic respiratory insufficiency [16, 14]. The use of positive end expiratory pressure (PEEP) enhances the patients' functional residual capacity allowing better gas exchange. Other studies have identified different predictive factors of NIV failure: ventilation-perfusion impairment, higher Pediatric Risk of Mortality score (PRISM), lower respiratory rate decrease,[18] presence of ARDS, higher
Pediatric Logistic Organ Dysfunction score, [19] and FiO2>80\%.[20]. The majority of patients showed significant improvement after one hour from application of NIV. The mean respiratory rate decreased from $48.4 \pm 2.2$ to $35.0 \pm 1.5(\mathrm{P}=0.000), \mathrm{O} 2$ concentration improved from 88.1 \pm 1.8 to $96.5 \pm 0.7(\mathrm{P}=0.000)$, and the $\mathrm{CO} 2$ concentration improved from $61.4 \pm 6.1$ to 48.7 \pm 3.7 ( $\mathrm{P}=0.002)$.Patients were monitored closely for signs of NIV failure and promptly intubated. Five patients were failed to respond to NIV after the initial one hour of monitoring, and were shifted to mechanical venlation. The diversity of predictors results from different study populations and from different factors chosen for evaluation. Although the number of patients was relatively low, we could report convincing efficacy of NIV in this pediatric patient population. Although there are numerous studies determining the factors predicting failure of NIPPV in acute respiratory failure and due to other causes, there is none from the Bangladeshi subcontinent and this study provides the Bangladeshi perspective on this issue. The strength of this study is the prospective nature of the study and the fact that robust statistical methods have been used for analysis of the data so that the results can be interpreted with confidence. Patients were monitored closely for signs of NIV failure and promptly intubated.

\section{LIMITATION OF THIS STUDY}

In this study, we chose one hour time as crucial point to decide whether to continue on NIV or to escalate to invasive ventilation. This needed an extended study with further point's time.

\section{CONClusion}

The NIV is a useful tool for treatment of respiratory failure in pediatrics, especially under the age of one year. Pneumonia was the commonest indication for the use of the NIV. NIV appears to be a well-tolerated alternative for use in the pediatric population. Its use is associated with decreased intubation rates, which may lead to a decrease in the intubationrelated complications. More investigation is needed to fully evaluate the ramifications of increased use of this technology in the PICU.

\section{REFERENCES}

[1] Armon K, Stephenson T, Gabriel V, MacFaul $\mathrm{R}$, Eccleston $\mathrm{P}$, Werneke U, Smith $\mathrm{S}$. Determining the common medical presenting problems to an accident and emergency department. Arch Dis Child. 2001; 84:390-392. 
[2] Dohna-Schwake C, Stehling F, Tschiedel E, Wallot M, Mellies U. Non-invasive ventilation on a pediatric intensive care unit: feasibility, efficacy, and predictors of success. PediatrPulmonol. 2011; 46:1114- 20.

[3] Schönhofer B1, Kuhlen R, Neumann P, Westhoff M, Berndt C, Sitter H. Clinicalpractice guideline. Non-invasive mechanical ventilation as treatment of acute respiratory failure: DtschArztebl Int. 2008; 105(24):424-33.

[4] Ambrosini N, Vagheggini G. Noninvasive positive pressure ventilation in the acute care setting: where are we? EurRespir J. 2008; 31:874-886.

[5] Antonelli M, Conti G, Rocco M, Bufi M, De Blasi RA, Vivino G, Gasparetto A, Meduri GU. A comparison of noninvasive positive-pressure ventilation and conventional mechanical ventilation in patients with acute respiratory failure. N Engl J Med. 1998; 339:429-435.

[6] Cavari Y, Sofer S, Rozovski U, Lazar I. Noninvasive positive pressure ventilation in infants with respiratory failure. PediatrPulmonol. 2012; 47:1019-25.

[7] Mortola JP, Fisher JT, Smith JB, Fox GS, Weeks S, Willis D. Onset of respiration in infants delivered by caesarean section. J Appl Physiol. 1982; 52:716-724.

[8] Thia LP, McKenzie SA, Blyth TP, Minasian CC, Kozlowska WJ, Carr SB. Randomised controlled trial of nasal continuous positive airways pressure (CPAP) in bronchiolitis. Arch Dis Child. 2008; 93:45-47.

[9] Rotta AT, Wiryawan B. Respiratory emergencies in children. Respir Care. 2003; 48:248-258.

[10] Teague WG. Noninvasive ventilation in the pediatric intensive care unit for children with acute respiratory failure. PediatrPulmonol. 2003; 35:418-426.

[11] Guslits BG, Gaston SE, Bryan MH, England SJ, Bryan AC. Diaphragmatic work of breathing in premature human infants. J Appl Physiol. 1987; 62:1410- 1415.

[12] Clara Abadesso, Pedro Nunes, Catarina Silvestre, Ester Matias, Helena Loureiro, and
Helena Almeida. Non-invasive ventilation in acute respiratory failure in children: Pediatr Rep. 2012; 4(2):e16.

[13] Essouri S, Durand P, Chevret L, Haas V, Perot C, Clement A, et al. Physiological effects of noninvasive positive ventilation during acute moderate hypercapnic respiratory insufficiency in children. Intensive Care Med. 2008; 34(12):2248-55.)

[14] Yañez LJ, Yunge M, Emilfork M, Lapadula M, Alcántara A, Fernández C, Lozano J, etal. A prospective, randomized, controlled trial of noninvasive ventilation in pediatric acute respiratory failure: PediatrCrit Care Med. 2008; 9(5):484-9.

[15] Muñoz-Bonet JI, Flor-Macián EM, Brines J, Roselló-Millet PM, Cruz Llopis M, López-Prats JL, Castillo S. Predictive factors for the outcome of noninvasive ventilation inpediatric acute respiratory failure: PediatrCrit Care Med. 2010;11(6):675-80.

[16] Essouri S, Chevret L, Durand P, Haas V, Fauroux B, Devictor D. Noninvasive positive pressure ventilation: five years of experience in a pediatric intensive care unit: PediatrCrit Care Med. 2006;7(4):329-34.

[17] Essouri S, Durand P, Chevret L, Haas V, Perot C, Clement A,Devictor D, Fauroux B. Physiological effects of non-invasivepositive ventilation during acute moderate hypercapnic respiratory insufficien -cy in children. Intensive Care Med 2008; 34 : 2248-2255.

[18] Mayordomo-Colunga J, Medina A, Corsino R, Di'az JJ, ConchaA, Los Arcos M, Mene'ndez S. Predictive factors of non invasiveventilation failure in critically ill children: a prospective epidemiological study. Intensive Care Med 2009; 35:527-536.

[19] Essouri S, Chevret L, Durand P, Haas V, Fauroux B, DevictorD. Noninvasive positive pressure ventilation: five years of experience in a pediatric intensive care unit. PediatrCritCareMed 2006; 7:32 9-334.

[20] Bernet V, Hug MI, Frey B. Predictive factors for the success of non-invasive mask ventilation in infants and children with acute respiratory failure. PediatrCrit Care Med 2005; 6:660-664.

Citation: Anima Ferdous, et.al., The Efficacy of NIV in Pediatric Intensive Care Unit (PICU) with Respiratory Failure Admitted Patients. ARC Journal of Pediatrics.2021; 7(1):1-5.Doi:dx.doi.org/ 10.2043 1/24555711.0701001.

Copyright: (C) 2021 Authors. This is an open-access article distributed under the terms of the Creative Commons Attribution License, which permits unrestricted use, distribution, and reproduction in any medium, provided the original author and source are credited. 